\title{
Adverse events in a new intensive care unit. Influence of healthcare facilities design and technology on incidence rates
}

Pablo Álvarez-Maldonado, ${ }^{*}$ Grisel Hernández-Ríos, ${ }^{1}$ Arturo Reding-Bernal and Raúl Cicero-Sabido' 'Department of Pulmonology and Thoracic Surgery; 'Department of Research, Hospital General de México "Dr. Eduardo Liceaga", Secretaria de Salud, Mexico City, Mexico

\begin{abstract}
Introduction: New hospitals are replacing old facilities. There is little information on the performance of an intensive care unit (ICU) when it is relocated in a new and equipped area. Objective: To analyze the impact of the change of ICU facilities from a shared environment to individual beds on the occurrence of adverse events. Method: Cross-sectional, comparative study, with prospectively collected data from patients admitted from March 01, 2014 to February 28, 2017 to the former ICU (f-ICU) and from July 17, 2017 to January 17, 2019 to the new ICU (n-ICU) of a public teaching hospital. The rate of adverse events was measured in events per 1,000 patient-days. Results: Among 1,188 patients (f-ICU, $n=681$ vs. $n$-ICU, $n=507$ ), a reduction in the rate of unforeseen cardiac arrest (rate ratio: $0.31 ; 95 \%$ confidence interval $[\mathrm{Cl}=0.12-0.80$ ) and an increase in the rate of unplanned extubation (rate ratio: $2.49 ; 95 \% \mathrm{Cl}=1.24-5.01$ ) were observed, with both being statistically significant. The other nine monitored adverse events showed no changes. Conclusions: In comparison with the f-ICU, most of the monitored adverse events did not significantly change within the first 18 months of activities at the $n-I C U$.
\end{abstract}

KEY WORDS: Adverse events. New facilities. Intensive care unit.

\section{Eventos adversos en una nueva unidad de cuidados intensivos. Influencia del diseño y la tecnología de las instalaciones en las tasas de incidencia}

\section{Resumen}

Introducción: Nuevos hospitales están reemplazando a instalaciones antiguas. Existe poca información del desempeño de una unidad de cuidados intensivos (UCl) cuando es reubicada en un área nueva y equipada. Objetivo: Analizar el impacto del cambio de instalaciones de un ambiente compartido a camas individuales en la ocurrencia de eventos adversos en la UCl. Método: Estudio transversal, comparativo, con datos prospectivos de pacientes ingresados del 1 de marzo de 2014 al 28 de febrero de 2017 a la antigua UCl (aUCl) y del 17 de julio de 2017 al 17 de enero de 2019 a la nueva UCI (nUCl) de un hospital-escuela público. La tasa de eventos adversos se midió en eventos por 1000 días-paciente. Resultados: En 1188 pacientes (aUCl, $n=681$ versus $n U C l, n=507$ ) se observó reducción en la tasa de paro cardiaco no previsto (razón de tasas 0.31, IC $95 \%=0.12-0.80$ ) e incremento en la tasa de extubación no planeada (razón de tasas 2.49, IC 95 \% = 1.24-5.01), estadísticamente significativos; los otros nueve eventos adversos monitoreados no mostraron cambios. Conclusiones: Comparada con la aUCl, la mayor parte de eventos adversos monitoreados no se modificaron significativamente en los 18 meses de inicio de actividades de la nUCl.

PALABRAS CLAVE: Eventos adversos. Nuevas instalaciones. Unidad de cuidados intensivos.

\footnotetext{
Correspondence:

*Pablo Álvarez-Maldonado

E-mail: pamyacs@yahoo.com

Gac Med Mex. 2019;155:569-574

Contents available at PubMed

www.gacetamedicademexico.com

0016-3813/@ 2019 Academia Nacional de Medicina de México, A.C.. Published by Permanyer. This is an open access article under the CC BY-NC-ND license (http://creativecommons.org/licenses/by-nc-nd/4.0/).
} 


\section{Introduction}

Adverse events are responsible for 400,000 deaths per year in hospitalized patients in the United States; they occur within a range of 2 to 4 million when they are not lethal. ${ }^{1}$ Intensive care units (ICUs) receive vulnerable patients who are treated by multiple healthcare providers, with sophisticated technologies, under stressful conditions and in often inappropriate environments that promote the occurrence of errors, and for this reason they are often referred to as "hostile environments". ${ }^{2,3}$ The design of facilities can play a key role in the mitigation of ICU hostile aspects. ${ }^{4-6}$ As new hospitals are built to replace old facilities, ICUs are being built with renewed technology and single rooms instead of the traditional open spaces for several patients. ${ }^{7} \mathrm{~A}$ strong association has been described between the design, the processes of care and the results when structural qualities such as single rooms, space and new technology are available in the ICU. ${ }^{8}$

With facilities dating from early in the $20^{\text {th }}$ century and equipment not in accordance with current standards, the Respiratory Intensive Care Unit (RICU) of the General Hospital of Mexico "Dr. Eduardo Liceaga" (the first specialty hospital in Mexico) was relocated on July 2017 in a completely new and equipped building within the hospital. The main purpose of this study is to investigate the impact of the RICU relocation on the occurrence of routinely monitored adverse events (AEs).

\section{Method}

Cross-sectional study with data prospectively obtained in a local database, where the rates of AEs occurred within an 18-month period from the start of activities at the new RICU (n-RICU), from July 17, 2017 to January 17,2019 , were compared with the rates within a previous three-year period at the former RICU prior to relocation (f-RICU), from March 1, 2014 to March 1, 2017.

Data from patients admitted to the RICU of the General Hospital of Mexico "Dr. Eduardo Liceaga", a public teaching hospital with 1131 beds, are included. The RICU, one of eight ICUs within the hospital, has healthcare personnel composed of an intensivist doctor or certified pulmonologist at each one of its shifts. The nurse to patient ratio is $1: 1$ to $1: 3$, whereas intensive care nurse to patient ratio is $1: 3$ to $1: 6$. In addition, there are also respiratory therapists (three distributed in different shifts) and an average of five pulmonology, internal medicine, emergency medicine, anesthesiology or critical medicine rotating residents. The n-RICU multidisciplinary team is the same the RICU had in the old building.

\section{Main differences in design and equipment between ICUs}

The former RICU (f-RICU) was located in an area adapted for use in a building dating back from early $20^{\text {th }}$ century, originally dedicated to the care of patients with tuberculosis. It had a common space with seven non-automatic beds, separated by curtains of synthetic material in an total area of $146 \mathrm{~m}^{2}$, one single entrance door for patients, relatives and healthcare personnel, which also served for ventilation (air inlet), a washbasin at the entrance to the unit, a heavy duty sink at the center of the unit, a bathroom with toilet for the disposal of organic fluids, equipment consisting of Spacelabs ${ }^{\circledR}$ mCare-300 monitors by each bed with invasive pressures display option and $\mathrm{Avea}^{\circledR}$ (Viasys) mechanical ventilators for invasive ventilation, which were acquired in 2009 during the influenza A (H1N1) pandemic. It had two recliners for common use by hospitalized patients. It had no rest area available for doctors nor an administrative area.

The n-RICU is located in the new building for the care of cardiorespiratory and vascular conditions; it was opened in July 2017 after a three-year construction period. The $\mathrm{n}-\mathrm{RICU}$ has an area of $530 \mathrm{~m}^{2}$, with 12 independent cubicles that are fully insulated with sliding glass doors and walls, as well as windows facing outside. Power outlets, medical air, oxygen and equipment are located on the back wall of the bedhead and each cubicle has washbasin, in addition to a fully automatic bed (InTouch $^{\circledR}$, Striker), a recliner, a vital signs monitor (IntelliVue $\mathrm{MX} 800^{\circledR}$, Philips) with options for cardiac output monitoring by PiCCO method, time capnography, bispectral index, pulse pressure variation, among others, and a mechanical ventilator with capacity to provide invasive and non-invasive ventilation (Puritan Bennett ${ }^{\mathrm{TM}}$ 840). There is an entrance with a washbasin as a "transfer" for health personnel and another for family members as well as an entrance door exclusively for patients on stretchers. The n-RICU also has a rest area for doctors and an administrative office within the unit itself. The whole unit has air conditioning, air injector and extractor. In addition, for the submission and reception of biological samples and medications there is a pneumatic system that communicates with different areas within the building. 
Table 1. Adverse events definitions

Accidental extubation

Pneumothorax

Unexpected cardiac arrest

Reintubation

Endotracheal tube change

Falls

Pressure ulcers

Hemorrhage due to stress ulcer

Deep vein thrombosis-pulmonary embolism

Atelectasis

Death in the ICU
Accidental removal of endotracheal tube by a doctor, a nurse or any other medical care staff member at the ICU that does not belong to a program or protocol, or accidental endotracheal tube extraction induced by the patient him/herself.

Presence of air or gas in the pleural cavity that causes lung collapse of any magnitude during ICU stay secondary to vascular puncture, thoracentesis or barotrauma.

Unexpected cardiac arrest that occurs in a patient without clinical deterioration within the last 24 hours of ICU stay. It requires evaluation by the medical staff on duty and by an experienced doctor of the ICU.

Reintubation within 48 to 72 hours after planned extubation.

Need to replace the endotracheal tube in a previously intubated patient due to occlusion or dysfunction at any place of the cannula.

Unplanned descent to the floor (or floor extension, e.g., trash can or other equipment), with or without injury. All types of falls are included, either for physiological or environmental reasons.

Lesions that can be classified in a grade or stage or of unknown depth, localized in the skin or underlying tissue as a result of pressure, or pressure in combination with stress in the skin that arise during the patient stay at the ICU.

Significant gastrointestinal bleeding with hemodynamic instability or transfusion requirement resulting from stress-related gastrointestinal mucosal disease.

Deep vein thrombosis or clinically and radiologically documented pulmonary embolism that originates during the patient stay at the ICU.

Lobar or total lung collapse due to any cause during the patient stay at the ICU. Segmental or "linear" atelectases are not included.

Death secondary to any cause during patient stay at the ICU. Patients with a do-not-resuscitate order and those with other therapeutic withhold or withdrawn orders are not included.
Gasometry processing and portable $\mathrm{X}$-ray takes with equipment available in situ were characteristic both at f-RICU and n-RICU.

\section{Data collection and statistical analysis}

Prospectively-collected data were taken from the DeDUCIR database, ${ }^{9}$ a computerized local database where information on demographics, severity and prognosis is recorded, in addition to AEs and variables for the calculation of quality indicators, among other information. The f-RICU data were obtained from a previous study in a period in which a multifaceted quality improvement program was implemented ${ }^{10}$ and from the DeDUCIR database. AE definitions are shown in Table 1. AE rates were calculated in events per 1000 patient-days. Patient sociodemographic and clinical characteristics are described using absolute and relative values (percentages) for dichotomous variables, and with medians and interquartile ranges $\left(25^{\text {th }}\right.$ to $75^{\text {th }}$ percentiles) for continuous variables that did not show a normal distribution according to the Kolmogorov-Smirnov test. Patient characteristics were compared with Pearson's chi-square test for dichotomous variables and Wilcoxon's rank-sum test for continuous variables, with the purpose to bivariately analyze possible statistically significant differences. To compare AE rates between n-RICU and f-RICU, the rate ratio with a $95 \%$ confidence interval $(\mathrm{Cl})$ was used. Statistical tests were carried out with the Stata ${ }^{\circledR}$ program, version 15 (StataCorp LLC, Texas, USA). In this study, no patient confidential information is reported, and its development was planned within the periodic quality reports of the institution, and therefore no additional approval by the institutional ethics and research committees or patient informed consent were required.

\section{Results}

Of the 1188 patients admitted to both ICUs in the study periods, 681 corresponded to the f-RICU and 507 to the n-RICU, with 5836 and 3011 patient-days at each period, respectively. 
Gaceta Médica de México. 2019;155

Table 2. Patient sociodemographic and clinical characteristics in both periods

\begin{tabular}{|c|c|c|c|c|c|}
\hline \multirow[t]{2}{*}{ Characteristic } & \multicolumn{2}{|c|}{ Former RICU ( $n=681)$} & \multicolumn{2}{|c|}{ New RICU ( $=507$ ) } & \multirow[t]{2}{*}{$p$} \\
\hline & Median & IQR & Median & IQR & \\
\hline Age (years) & 49 & $38-61$ & 51 & $39-62$ & 0.113 \\
\hline SAPS 3 & 52 & $37-65$ & 54 & $40-68$ & 0.008 \\
\hline SOFA & 5 & $1-9$ & 4 & $1-9$ & 0.822 \\
\hline ICU stay (days) & 5.3 & $2.7-10.6$ & 3.08 & $1.25-7.1$ & $<0.001$ \\
\hline & $\mathrm{n}$ & $\%$ & $\mathrm{n}$ & $\%$ & \\
\hline Male gender & 361 & 53 & 265 & 52 & 0.800 \\
\hline Mechanical ventilation & 391 & 57.4 & 252 & 49.7 & 0.008 \\
\hline $\begin{array}{l}\text { Reason for ICU admission } \\
\text { Respiratory } \\
\text { Postoperative } \\
\text { Cardiovascular } \\
\text { Neurological } \\
\text { Renal } \\
\text { Metabolic } \\
\text { Hematological } \\
\text { Hepatic }\end{array}$ & $\begin{array}{l}342 \\
219 \\
95 \\
15 \\
8 \\
1 \\
0 \\
1\end{array}$ & $\begin{array}{c}50.2 \\
32.2 \\
14 \\
2.2 \\
1.2 \\
0.1 \\
0 \\
0.1\end{array}$ & $\begin{array}{c}252 \\
91 \\
128 \\
15 \\
10 \\
4 \\
4 \\
2\end{array}$ & $\begin{array}{c}49.7 \\
17.9 \\
25.2 \\
3.0 \\
2.0 \\
0.8 \\
0.8 \\
0.4\end{array}$ & $\begin{array}{c}0.860 \\
<0.001 \\
<0.001 \\
0.411 \\
0.266 \\
0.091 \\
0.020 \\
0.400\end{array}$ \\
\hline
\end{tabular}

RICU = respiratory intensive care unit, IQR = interquartile range (25-75), SAPS-3 = simplified acute physiology score 3, SOFA = sequential organ failure assessment.

Table 3. Adverse event rate ratio

\begin{tabular}{|c|c|c|c|c|c|}
\hline \multirow[t]{2}{*}{ Adverse event } & \multicolumn{2}{|c|}{ Rate of events per 1000 patient-days } & \multirow[t]{2}{*}{ Rate ratio } & \multirow[t]{2}{*}{$95 \% \mathrm{Cl}$} & \multirow[t]{2}{*}{$\mathbf{p}^{*}$} \\
\hline & $\begin{array}{c}\text { Former RICU } \\
\text { (5836 patient-days) }\end{array}$ & $\begin{array}{c}\text { New RICU } \\
\text { (3011 patient-days) }\end{array}$ & & & \\
\hline Accidental extubation & 2.39 & 5.97 & 2.49 & $1.24-5.01$ & 0.014 \\
\hline Pneumothorax & 2.39 & 1.32 & 0.55 & $0.13-1.76$ & 0.152 \\
\hline Unexpected cardiac arrest & 5.31 & 1.66 & 0.31 & $0.12-0.80$ & 0.018 \\
\hline Reintubation & 4.79 & 4.31 & 0.90 & $0.47-1.74$ & 0.881 \\
\hline Endotracheal tube change & 0.86 & 1.99 & 2.33 & $0.59-9.63$ & 0.311 \\
\hline Falls & 0.17 & 0 & 0 & - & - \\
\hline Pressure ulcers & 15.93 & 11.6 & 0.73 & $0.49-1.08$ & 0.133 \\
\hline Bleeding from stress ulcers & 3.59 & 3.32 & 0.92 & $0.43-1.96$ & 0.985 \\
\hline DVT/PTE & 0.17 & 0.33 & 1.94 & $0.02-152.14$ & 0.242 \\
\hline Atelectasis & 2.22 & 1.33 & 0.60 & $0.14-1.93$ & 0.137 \\
\hline Death in RICU & 37.35 & 44.1 & 1.18 & $0.95-1.47$ & 0.142 \\
\hline
\end{tabular}

$\mathrm{Cl}=$ confidence interval, RICU, respiratory intensive care unit, DVT/PTE - deep vein thrombosis/pulmonary thromboembolism. ${ }^{*} \mathrm{~A} P$ value $>0.05$ indicated statistical significance.

Patient sociodemographic and clinical characteristics at both periods are shown in Table 2, and AE rates and their comparison, in Table 3. A statistically significant reduction was observed in the rate of unexpected cardiac arrest and an increase in the rate of unplanned of extubation. The remaining nine monitored AEs did not show statistically significant differences. According to the number of patients included in each period, $49 \%$ more admissions per month were observed during the period corresponding to the 
$\mathrm{n}-\mathrm{RICU}$, in comparison with that of care at the f-RICU. Mortality in the ICU was not different in both periods when the analysis was made comparing adverse event rates; however, a mortality difference was identified when the proportions of deceased subjects were compared between periods at the f-RICU and the n-RICU: mortality of $32 \%$ versus $26.2 \%$, respectively $(p=0.036)$.

\section{Discussion}

Any harm to the patient resulting from medical handling is considered an adverse event. ${ }^{11}$ ICU patients are particularly prone to AEs given their unstable condition and the requirement of multiple interventions. Attributes of the ICU design, such as appropriate light and space, noise control and single rooms have shown a strong association with better survival outcomes. ${ }^{8}$ It has also been observed that these attributes, together with the use of new technologies, can favorably impact on the processes of care.12 Despite looking for an association between RICU structural and equipment change and a lower occurrence of errors, most of the monitored AEs were not significantly modified in this analysis, except for the rate of unexpected cardiac arrest, which showed a decrease, and the rate of unplanned extubation, which showed an increase.

In all the world, old health facilities are being replaced or renewed to adapt to medical care services new requirements, including increased numbers of beds, technological advances and the need for patient privacy. ${ }^{7,13}$

Due to the unique conditions of ICU patients, it is reasonable to assume that the relocation and subsequent transition of the personnel to a new work environment can be more complex than for other hospital departments. The transition is a process that requires adaptation to the environment and is considered one of the most complex projects of change management. ${ }^{14,15}$ A study that assessed the perception of healthcare personnel when a hospital moved from shared rooms to single rooms found that the new model increased the workload for doctors and nurses, and that stress in the staff did progressively increase during the first 15 months post-change. ${ }^{16}$ In a more recent study, Lin et al. ${ }^{7}$ identified health personnel concerns about patient safety when relocated in a geographically and structurally new ICU with single rooms, among which the fact that nurses were unable to get the necessary help, loss of supervision of less experienced personnel and the requirement of an increased use of sedation and physical restraints to prevent events such as self-extubation stand out. Indeed, these factors might have influenced the unplanned extubation rate in the present analysis, which had a significant increase. In addition to the limitations in the visual field of surveillance and distance from the patients imposed by the new RICU structure, the medical and nursing staff was the same to serve almost twice the beds and $49 \%$ more admissions per month.

It is necessary to consider that, during the analyzed period, a multifaceted quality improvement program was implemented in the f-RICU, which led to a reduction in five of eleven $\mathrm{AE}$ rates and increased survival. ${ }^{10}$ Although n-RICU patients were more severely ill at admission (according to the SAPS 3 scale) and had more cardiovascular conditions, they had fewer patients under mechanical ventilation and less ICU stay, without mortality significantly varying when it was regarded as an adverse event (events per 1000 patient-days). Moreover, when the proportions of deceased subjects are compared in both periods (as it is usually done to assess the clinical performance of an ICU or hospital department), mortality was lower in the period corresponding to the start of activities at the n-RICU. Therefore, we believe that the RICU had a successful transition to the new building and that it is possible to significantly reduce the rates of $A E$ and other indicators with the implementation of improvement projects, organizational change and by hiring sufficient personnel according to the new structure. 10,17-19

As regards the significant decrease in the rate of unexpected cardiac arrest, we attribute this fact to the possibility that with more and better technology at the $\mathrm{n}-\mathrm{RICU}$, and with more sensitive alarm systems, changes in the clinical condition that precede these events may have been early recognized, unlike other AEs. Continuous vital signs monitoring with adequate surveillance equipment is known to reduce the possibility of unexpected death secondary to preventable complications in hospitalized patients. ${ }^{20,21}$

There are some limitations of this study that deserve to be commented, such as the difficulty to know how many days the patients were at risk of suffering each adverse event. In addition, the analysis corresponds to a single ICU with admission of patients predominantly presenting with respiratory pathology, and the results may therefore not be susceptible to be generalized to other settings. Nevertheless, the present work contributes to the understanding of the 
impact of new intensive care facilities in outcome measures such as AEs and complements available information on the performance of new buildings for those participating in the transition from an ICU with shared rooms to an ICU with individual rooms.

This study suggests that despite having environments with "friendly" designs and cutting-edge technological support, the safety of the critically ill patient in single rooms should be taken into account. The transition to new facilities, in addition to being accompanied by changes in the processes of care, requires assigning enough staff to meet the new demands. Relocation of an ICU, which is a stressful and demanding process, can result in risk for the patient, his/her relatives and the healthcare staff itself. Achieving a steady state in the outcomes of indicators such as AEs can be the starting point of a successful transition to a new physical area.

\section{Statement}

The authors deny any competing interests or financial conflicts related to the preparation of this work. Its development adheres to the ethical requirements of the institution where it was carried out.

\section{References}

1. Makary MA, Daniel M. Medical error-the third leading cause of death in the US. BMJ. 2016;353:i2139.

2. Donchin Y, Gopher D, Olin M, Badihi Y, Biesky M, Sprung CL, et al. A look into the nature and causes of human errors in the intensive care unit. Crit Care Med. 2003;12:143-147.

3. Donchin Y, Seagull FJ. The hostile environment of the intensive care unit. Curr Opin Crit Care. 2002:8:316-320.
4. Zirming $\mathrm{C}$, Bosch $\mathrm{S}$. Building the evidence base for evidence-based design: editors' introduction. Environ Behav. 2008:40:147-150.

5. Ulrich RS, Zimring C, Zhu X, DuBose J, Seo HB, Choi YS, et al. A review of the research literature on evidence-based healthcare design. HERD. 2008;1:61-125.

6. Jongerden IP, Slooter AJ, Peelen LM, Wessels H, Ram CM, Kesecioglu J, et al. Effect of intensive care environment on family and patient satisfaction: a before-after study. Intensive Care Med. 2013; 39:1626-1634.

7. Lin FF, Foster M, Chaboyer W, Marshall A. Relocating an intensive care unit: an exploratory qualitative study. Aust Crit Care. 2016;29:55-60.

8. Ferri M, Zygun DA, Harrison A, Stelfox HT. A study protocol for performance evaluation of a new academic intensive care unit facility: impact on patient care. BMJ Open. 2013;3:e003134.

9. Álvarez-Maldonado P, Cueto-Robledo G, Cerón-Díaz U, Pérez-Rosales A, Navarro-Reynoso F, Cicero-Sabido R. Indicadores de calidad en una unidad de cuidados intensivos respiratorios. Análisis inicial de la base de datos DEDUCIR. Med Intensiva. 2012;36:518-520.

10. Álvarez-Maldonado P, Reding-Bernal A, Hernández-Solís A, Cicero-Sabido R. Impact of strategic planning, organizational culture imprint and care bundles to reduce adverse events in the ICU. Int J Qual Health Care. 2019:31:480-484.

11. Rothschild JM, Landrigan CP, Cronin JW, Kaushal R, Lockley SW, Burdick E, et al. The Critical Care Safety Study: the incidence and nature of adverse events and serious medical errors in intensive care. Crit Care Med. 2005;33:1694-1700.

12. Darley ESR, Vasant J, Leeming J, Hammond F, Matthews S, Albur M, et al. Impact of moving to a new hospital build, with a high proportion of single rooms, on healthcare-associated infections and outbreaks. J Hosp Infect. 2018:98:191-193.

13. Parent JB. Moving technology into your new hospital: top 10 things to know. Advice for maintaining a sound strategy during a complex expansion. Healthc Inform. 2012;29:24-25.

14. Tussey KR, Yackzan SG, Davies CC. Moving into a new hospital tower: the MOVEE model. Nurse Manage. 2018;49:12-16.

15. Slosberg M, Nejati A, Evans J, Nanda U. Transitioning to a new facility: the crucial role of employee engagement. J Healthc Manag. 2018;63:63-77.

16. Maguire J, Burger K, O'Donnel P, Parnell L. Clinician perceptions of a changing hospital environment. HERD. 2013;6:69-79.

17. Munich RL. Transplanting an organization: how does culture matter. Bull Menninger Clin. 2011;75:126-144.

18. Fairbrother $\mathrm{G}$, Jones A, Rivas K. Changing model of nursing care from individual patient allocation to team nursing in the acute inpatient environment. Contemp Nurse. 2010;35:202-220.

19. Neuraz A, Guérin C, Payet C, Polazzi S, Aubrun F, Dailler F, et al. Patient mortality is associated with staff resources and workload in the ICU: a multicenter observational study. Crit Care Med. 2015;43:1587-1594.

20. Verrillo SC, Winters BD. Review: continuous monitoring to detect failure to rescue in adult postoperative inpatients. Biomed Instrum Technol. 2018:52:281-287.

21. Eytan D, Goodwin A, Laussen P, Guerguerian AM. Insights from multi-dimensional physiological signals to predict and prevent cardiac arrests. Pediatr Crit Care Med. 2016;17:81-82. 